\title{
Perbandingan Perencanaan Pondasi Tiang Pancang Menggunakan Metode Konvensional dan Metode $P$-Z Curve pada Modifikasi Gedung Apartemen Puncak MERR Surabaya
}

\author{
Riky Dwi Prasetyo, Indrasurya B. Mochtar, Yudhi Lastiasih \\ Departemen Teknik Sipil, Fakultas Teknik Sipil, Lingkungan, dan Kebumian, \\ Institut Teknologi Sepuluh Nopember \\ e-mail: indrasurya@ce.its.ac.id
}

\begin{abstract}
Abstrak-Surabaya merupakan kota dengan pertumbuhan ekonomi besar yang selalu di atas rata-rata pertumbuhan ekonomi nasional. Banyak penduduk dari luar Surabaya datang ke kota ini sebagai pendatang tiap tahunnya untuk melaksanakan kegiatan ekonomi. Keterbatasan lahan yang ada menuntut perlunya pembangunan bangunan vertikal untuk tempat tinggal, salah satunya adalah Apartemen Puncak MERR yang memiliki kedalaman tanah keras yang cukup dalam sehingga biaya yang harus dikeluarkan untuk pondasi dalam cukup besar. Pada pembangunan gedung dengan pondasi dalam, semakin dalam pondasi maka semakin mahal biaya sehingga tidak ekonomis. Pada metode perencanaan konvensional, perletakan untuk kolom struktur atas terhadap pondasi dianggap jepit dan tidak ada penurunan (settlement) pada tanah. Pada tanah lempung yang bersifat compressible, pengaruh beban akan menyebabkan terjadinya penurunan tanah sehingga muncul konsep perhitungan tiang pancang yang memperhatikan penurunan tanah dan menganggap perletakan struktur atas berupa perletakan pegas dengan metode $\mathbf{P}-\mathrm{Z}$ curve. Dengan memperhatikan adanya penurunan tanah akan menyebabkan kedalaman tiang pancang berkurang. Metode perencanaan yang digunakan yaitu konvensional jepit dan P-Z curve pegas. Variasi daya dukung yang digunakan pada perencanaan ini yaitu $\mathrm{SF}=3$ untuk metode konvensional dan Qizin = 0,3 Qult, Qizin = 0,5 Qult, Qizin = 0,7 Qult, dan Qizin = 0,9 Qult pada metode $\mathrm{P}-\mathrm{Z}$ curve. Perencanaan pondasi tiang pancang pancang menggunakan spun pile diameter $60 \mathrm{~cm}$. Kedalaman tanah daya dukung yaitu $21 \mathrm{~m}$ untuk pondasi end bearing dan $16 \mathrm{~m}$ untuk pondasi friction. Dari hasil perhitungan didapat jumlah kebutuhan tiang pancang pada metode P-Z curve lebih sedikit dibandingkan dengan mretode konvensional. Hasil dari perencanaan ini adalah mendapatkan variasi alternatif hasil analisis metode perencanaan pondasi dalam dengan metode konvensional dan metode $\mathrm{P}-\mathrm{Z}$ curve. Untuk menghemat biaya pembangunan gedung modifikasi Apartemen Puncak MERR maka digunakan pondasi tiang pancang dengan metode $\mathrm{P}-\mathrm{Z}$ Curve tumpuan end bearing dengan Qizin = 0,9 Qult.
\end{abstract}

Kata Kunci-Pondasi Tiang Pancang, Metode Konvensional, Metode P-Z curve, Settlement, Biaya.

\section{PENDAHULUAN}

$S^{-}$ URABAYA adalah ibukota Provinsi Jawa Timur dan merupakan kota dengan pertumbuhan ekonomi besar yang selalu di atas rata-rata pertumbuhan ekonomi nasional. Berdasarkan data jumlah penduduk pada tahun 2016, kepadatan penduduk kota Surabaya cukup tinggi, mencapai 8,12 jiwa $/ \mathrm{km}^{2}$ [1] Selain itu, banyak penduduk dari luar
Surabaya datang ke kota ini sebagai pendatang tiap tahunnya untuk melaksanakan kegiatan ekonomi. Menurut data BPS Surabaya, jumlah pendatang di Kota Surabaya pada rentang tahun 2009 - 2014 mencapai 398.143 orang [1]. Di sisi lain, dikutip dari Bappeda Jatim, lahan pertanian di Surabaya menyusut rata-rata 66 hektar per tahun pada tahun 2012 dan diperkirakan akan habis pada tahun 2030. Keterbatasan lahan tersebut menyebabkan semakin banyak pembangunan gedung hunian vertikal/ apartemen karena dirasa lebih efisien dalam memenuhi kebutuhan tempat tinggal. Salah satu gedung apartemen yang dibangun di Surabaya adalah Apartemen Puncak MERR, perpaduan antara pertokoan, perkantoran, apartemen, dan hotel yang dibangun di daerah MERR (Middle East Ring Road), Surabaya.

Pada pembangunan gedung dengan pondasi dalam, semakin dalam pondasi maka semakin mahal biaya sehingga tidak ekonomis. Saat ini metode perencanaan pondasi dalam yang sering digunakan adalah dengan menggunakan metode end bearing pile dimana tiang pancang dianggap menyalurkan beban sampai pada tanah keras (tumpuan ujung) dan metode friction pile dimana daya dukung terjadi akibat interaksi pondasi-tanah pada sisi tiang pancang sebagai gaya gesek (tumpuan gesek)

Apartemen Puncak MERR memiliki kedalaman tanah yang cukup dalam sehingga biaya yang harus dikeluarkan untuk pondasi dalam cukup besar [2]. Pada metode perencanaan konvensional, perletakan untuk kolom struktur atas terhadap pondasi dianggap jepit dan tidak ada penurunan (settlement) pada tanah. Pada tanah lempung yang bersifat compressible, pengaruh beban akan menyebabkan terjadinya penurunan tanah sehingga muncul konsep perhitungan tiang pancang yang memperhatikan penurunan tanah dan menganggap perletakan struktur atas berupa perletakan pegas dengan metode $P-Z$ curve. Dengan memperhatikan adanya penurunan tanah akan menyebabkan kedalaman tiang pancang berkurang [3].

Dari kasus di atas, maka dilakukan perencanaan pondasi pada gedung modifikasi Apartemen Puncak MERR dengan membandingkan metode konvensional (perletakan jepit) dengan metode $P-Z$ curve (perletakan pegas) serta dampaknya terhadap pemampatan yang terjadi dan pengaruh terhadap momen/ defleksi struktur atas. Dengan demikian dapat diperoleh alternatif perencanaan untuk analisis perbandingan harga sehingga didapatkan metode perencanaan yang paling ekonomis. 


\section{METODOLOGI}

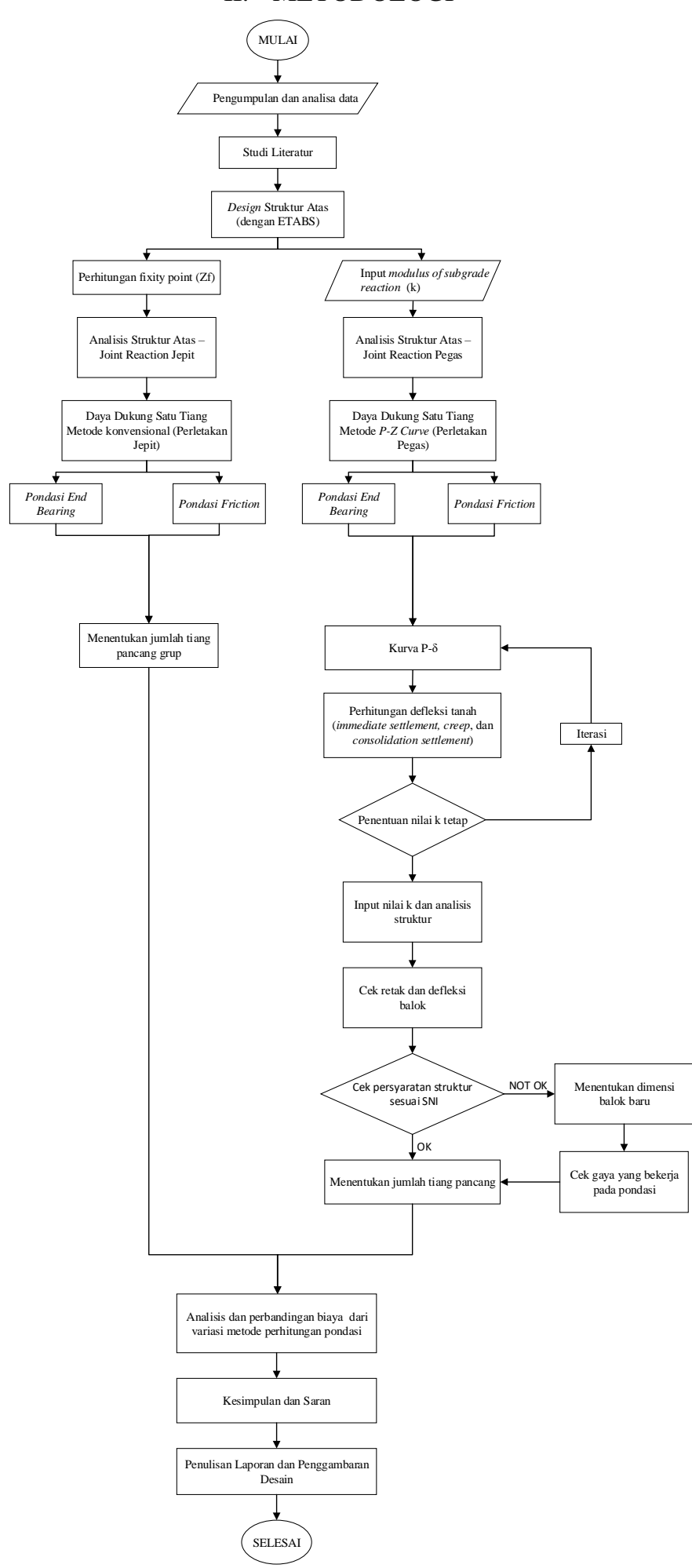

Gambar 1. Flowchart Metodologi.

\section{ANALISIS DATA}

\section{A. Pengumpulan dan Analisis Data Tanah}

Data tanah untuk pengerjaan perencanaan ini didapat dari kontraktor proyek pembangunan Apartemen Puncak MERR. Lokasi proyek berada di Wonorejo, Surabaya. Data hasil Standard Penetration Test dibuat perbandingan grafik hubungan $\mathrm{N}_{\mathrm{spt}}$ dan kedalaman tanah. Dari hasil Standard Penetration Test dan Bore Log dapat diketahui jenis tanah dan konsistensi tanah untuk masing-masing titik (Gambar 2) [2].

\begin{tabular}{|c|c|c|c|c|c|c|c|c|}
\hline \multirow{2}{*}{ Depth Z } & \multicolumn{8}{|c|}{ Consistency } \\
\hline & DB1 & DB2 2 & DB3 & DB 4 & DB5 & DB 6 & DB7 & DB 8 \\
\hline \multicolumn{9}{|l|}{0} \\
\hline 1 & Soft & Very Soft & Very Soft & Very Soft & Very Soft & Very Soft & Soft & Soft \\
\hline \multicolumn{9}{|l|}{2} \\
\hline 3 & Very Soft & Very Soft & Very Soft & Very Soft & Very Soft & Very Soft & Very Soft & Very Soft \\
\hline \multicolumn{9}{|l|}{4} \\
\hline 5 & Very Soft & Very Soft & Very Soft & Soft & Very Soft & Very Soft & Very Soft & Very Soft \\
\hline \multicolumn{9}{|l|}{6} \\
\hline 7 & Very Soft & Very Soft & Very Soft & Very Soft & Very Soft & Very Soft & Very Soft & Very Soft \\
\hline \multicolumn{9}{|l|}{8} \\
\hline 9 & Very Soft & Very Soft & Very Soft & Very Loose & Very Soft & Very Soft & Very Soft & Very Soft \\
\hline \multicolumn{9}{|l|}{10} \\
\hline 11 & Stiff & Medium & Medium & Medium & Medium & Veryloose & Loose & Loose \\
\hline \multicolumn{9}{|l|}{12} \\
\hline 13 & Stiff & Stiff & Stiff & Stiff & Stiff & Medium & Medium & Stiff \\
\hline \multicolumn{9}{|l|}{14} \\
\hline 15 & Medium & Stiff & Very Dense & Very Stiff & Stiff & Very Stiff & Stiff & Stiff \\
\hline \multicolumn{9}{|l|}{16} \\
\hline 17 & Very Dense & Very Stiff & Very Stiff & Medium & Very Stiff & Hard & Hard & Very Stiff \\
\hline \multicolumn{9}{|l|}{18} \\
\hline 19 & Very Stiff & Very Dense & Very Dense & Dense & Very Stiff & Very Stiff & Very Stiff & Stiff \\
\hline \multicolumn{9}{|l|}{20} \\
\hline 21 & Very Stiff & Very Stiff & Hard & Dense & Dense & Very Dense & Very Dense & Medium \\
\hline \multicolumn{9}{|c|}{\begin{tabular}{|c|c|c|c|} 
&
\end{tabular}} \\
\hline 23 & Very Stiff & Very Stiff & Very Stiff & Very Stiff & Dense & Very Dense & Dense & Dense \\
\hline \multicolumn{9}{|l|}{24} \\
\hline 25 & Hard & Very Stiff & Very Stiff & Very Stiff & Very Stiff & Very Stiff & Stiff & Dense \\
\hline \multicolumn{9}{|l|}{26} \\
\hline 27 & Very Stiff & Very Stiff & Hard & Medium & Medium & Very Stiff & Very Stiff & Very Stiff \\
\hline \multicolumn{9}{|l|}{28} \\
\hline 29 & Very Stiff & Very Stiff & Very Stiff & Hard & Very Stiff & Dense & Very Stiff & Very Stiff \\
\hline 30 & & & & & & & & \\
\hline
\end{tabular}

Gambar 2. Perbandingan jenis dan konsistensi tanah antar titik penyelidikan tanah.

Dari perbandingan $\mathrm{N}_{\mathrm{SPT}}$ dan jenis-konsistensi tanah pada Gambar 2 maka dipilih tanah dengan kondisi paling kritis yaitu tanah titik DB-8. Data tanah DB-8 ini akan digunakan sebagai data tanah untuk perencanaan dan pengerjaan perencanaan ini.

Data tanah yang berasal dari proyek untuk perencanaan ini hanya berupa data $\mathrm{N}_{\mathrm{SPT}}$ dan Bore Log sehingga diperlukan analisis untuk mencari data parameter tanah yang lain dengan cara korelasi sesuai jenis tanah dan $\mathrm{N}_{\text {SPT }}$. Nilai parameter tanah dibagi menjadi layer per kedalaman tertentu berdasarkan jenis dan konsistensi tanah.

\section{B. Perancangan dan Analisis Struktur Atas}

Rancangan struktur atas untuk perencanaan ini didapat dari data proyek yang kemudian dimodifikasi. Permodelan struktur bertujuan untuk mendapatkan reaksi perletakan yang nantinya akan digunakan sebagai beban untuk perencanaan pondasi. Hasil perancangan struktur atas dimodelkan ke dalam ETABS untuk dilakukan analisis struktur (Gambar 2). Analisis struktur ini bertujuan untuk cek kondisi struktur dan untuk mendapatkan reaksi perletakan struktur. Titik tumpuan untuk perletakan struktur pada gedung ini berjumlah 182 titik.

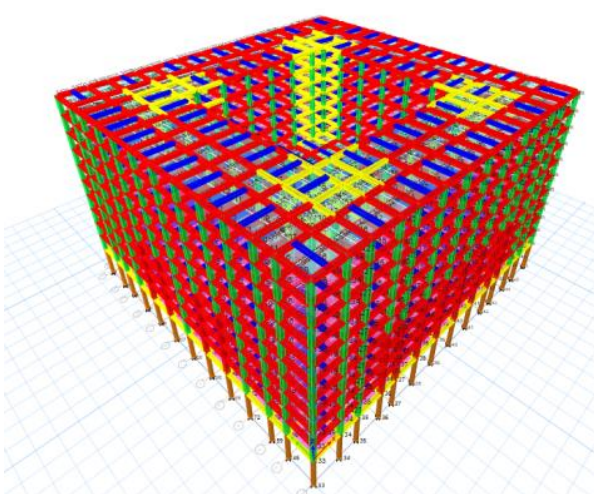

Gambar 2. Model struktur atas. 
Dari hasil input model struktur gedung, program ETABS akan menentukan penomoran label perletakan (joint label). Dari posisi dan koordinat perletakan tersebut, dibuat Tabel berisi label perletakan sesuai sumbu posisi perletakan tersebut (Tabel 1). Tabel ini akan digunakan acuan untuk menampilkan hasil perhitungan pada perletakan pada pembahasan selanjutnya.

Tabel 1.

Label perletakan sesuai sumbu koordinat pada ETABS

\begin{tabular}{ccccccccccccccc}
\hline \hline Axis & A & B & C & D & E & F & G & H & I & J & K & L & M & N \\
\hline 1 & 133 & 134 & 135 & 136 & 137 & 138 & 139 & 140 & 141 & 142 & 143 & 144 & 145 & 26 \\
2 & 146 & 147 & 148 & 149 & 150 & 151 & 152 & 153 & 154 & 155 & 156 & 157 & 158 & 25 \\
3 & 159 & 160 & 161 & 162 & 163 & 164 & 165 & 166 & 167 & 168 & 169 & 170 & 171 & 24 \\
4 & 172 & 173 & 174 & 175 & 176 & 177 & 178 & 179 & 180 & 181 & 182 & 183 & 184 & 23 \\
5 & 185 & 186 & 187 & 188 & 189 & 190 & 191 & 192 & 193 & 194 & 195 & 196 & 197 & 22 \\
6 & 198 & 199 & 200 & 201 & 202 & 203 & 204 & 205 & 206 & 207 & 208 & 209 & 210 & 21 \\
7 & 120 & 121 & 122 & 123 & 124 & 125 & 126 & 127 & 128 & 129 & 130 & 131 & 132 & 20 \\
8 & 107 & 108 & 109 & 110 & 111 & 112 & 113 & 114 & 115 & 116 & 117 & 118 & 119 & 19 \\
9 & 94 & 95 & 96 & 97 & 98 & 99 & 100 & 101 & 102 & 103 & 104 & 105 & 106 & 18 \\
10 & 81 & 82 & 83 & 84 & 85 & 86 & 87 & 88 & 89 & 90 & 91 & 92 & 93 & 17 \\
11 & 68 & 69 & 70 & 71 & 72 & 73 & 74 & 75 & 76 & 77 & 78 & 79 & 80 & 16 \\
12 & 55 & 56 & 57 & 58 & 59 & 60 & 61 & 62 & 63 & 64 & 65 & 66 & 67 & 15 \\
13 & 1 & 2 & 3 & 4 & 5 & 6 & 7 & 8 & 9 & 10 & 11 & 12 & 13 & 14 \\
\hline \hline
\end{tabular}

Pada metode konvensional perletakan struktur berupa jepit (fixed joint) dimana perletakan struktur tidak mengalami translasi maupun rotasi, sehingga reaksi perletakan menghasilkan rekasi arah vertikal, horizontal, dan momen. Di sisi lain, perletakan jepit ini menghasilkan translasi dan rotasi nol sehingga struktur gedung diasumsikan tidak mengalami displacement baik arah vertikal maupun horizontal.

Pada metode $P-Z$ Curve perletakan struktur berupa pegas (spring joint) dimana perletakan struktur dianggap elastis, dimana faktor displacement pada perletakan diperhitungkan. Hal ini disebabkan karena secara aktual, tanah lunak selalu mengalami displacement jika dibebani. Pada perencanaan ini, displacement yang diperhitungkan hanya pada arah vertikal (penurunan tanah). Hal ini menyebabkan reaksi yang terjadi pada perletakan pegas hanya rekasi vertikal, sedangkan reaksi horizontal dan momen bernilai nol. Pada ETABS, fungsi yang dipakai adalah fungsi point spring dimana satu titik perletakan dimasukkan satu spring.

\section{Perhitungan Daya Dukung Tanah}

Perhitungan daya dukung tanah pada perencanaan perencanaan ini dihitung menggunakan program bantu Allpile. Program Allpile menghitung daya dukung tanah menggunakan metode NAVFAC DM-7 [4][5]. Alasan pemakaian program Allpile untuk perhitungan daya dukung tanah ini adalah agar tidak terjadi penyimpangan terhadap bentuk kurva load-settlement yang akan digunakan pada metode $P$-Z Curve.

Nilai daya dukung tanah yang dihasilkan berupa daya dukung tanah ultimate harus dibagi dengan faktor keamanan SF (safety factor)/ load rasio. Untuk perencanaan metode konvensional digunakan $\mathrm{Q}_{\text {izin }}$ dengan $\mathrm{SF}=3$. Sedangkan pada metode $P-Z$ curve digunakan $\mathrm{Q}_{\text {izin }}$ dengan variasi $0,3 \mathrm{Q}_{\text {ult }}, 0,5$ $\mathrm{Q}_{\text {ult, }}$ 0,7 Qult, dan 0,9 Qult. Nilai daya dukung tanah untuk perencanaan ini dapat dilihat pada Tabel 3.

Dari nilai daya dukung izin, maka perlu dikontrol kekuatan aksial dari tiang pancang yang dipilih (WIKA Spun Pile diameter $60 \mathrm{~cm})$. Kontrol kekuatan aksial dirumuskan sebagai berikut:

$$
\mathrm{P}_{\text {allowable }} \geq \mathrm{Q}_{\text {izin }}
$$

Nilai $\mathrm{P}_{\text {allowable }}$ untuk tiang pancang yang dipilih adalah 2527 kN. Kontrol untuk masing-masing $Q_{\text {izin }}$ disajikan pada Tabel 2.
Tabel 2.

Nilai daya dukung dan kontrol kekuatan aksial tiang pancang terhadap $\mathrm{Q}_{\mathrm{izin}}$ masing-masing metode perencanaan

\begin{tabular}{cccc}
\hline \hline Metode & $\mathrm{Q}_{\text {izin }}(\mathrm{kN})$ & $\mathrm{P}_{\text {allowable }}(\mathrm{kN})$ & Kontrol \\
\hline Konvensional End Bearing & 758,6 & 2527 & OK \\
Konvensional Friction & 310,64 & 2527 & OK \\
P-Z Curve End Bearing 0,3 Ult & 682,74 & 2527 & OK \\
P-Z Curve End Bearing 0,5 Ult & 1137,9 & 2527 & OK \\
P-Z Curve End Bearing 0,7 Ult & 1593,06 & 2527 & OK \\
P-Z Curve End Bearing 0,9 Ult & 2048,22 & 2527 & OK \\
P-Z Curve Friction 0,3 Ult & 279,57 & 2527 & OK \\
P-Z Curve Friction 0,5 Ult & 465,95 & 2527 & OK \\
P-Z Curve Friction 0,7 Ult & 652,33 & 2527 & OK \\
P-Z Curve Friction 0,9 Ult & 838,71 & 2527 & OK \\
\hline \hline
\end{tabular}

\section{PERENCANAAN GEOTEKNIK}

Pada tahap ini dilakukan perencanaan pondasi tiang pancang metode konvensional dan $P-Z$ Curve. Perhitungan dilakukan untuk masing-masing jenis tiang pancang end bearing dan friction. Pondasi tiang pancang end bearing menggunakan ujung pondasi sebagai kekuatan daya dukungnya. Sedangkan pondasi friction menganggap tiang pancang diletakkan tidak sampai menyentuh tanah keras. Pondasi tiang pancang friction menggunakan lekatan tanah pada sepanjang selimut pondasi sebagai kekuatan daya dukungnya.

Perhitungan daya dukung pondasi metode konvensional yaitu dengan asumsi tidak ada penurunan pada tiang pancang $(\Delta \approx 0)$. Pada input ETABS pondasi ini diasumsikan sebagai perletakan jepit. Perhitungan kekuatan pondasi perletakan pegas metode $P-Z$ curve yaitu dengan dengan asumsi adanya penurunan/ settlement pada tiang pancang $(\Delta \neq 0)$. Besarnya daya dukung tanah diasumsikan memiliki daya dukung izin bervariasi sesuai load rasio yaitu 0,$3 ; 0,5 ; 0,7$; dan 0,9 daya dukung ultimate tanah. Pada input ETABS pondasi ini diasumsikan sebagai perletakan pegas.

Perencanaan jumlah tiang pancang dilakukan setelah mengetahui daya dukung pada satu pondasi tiang pancang untuk masing-masing metode perencanaan dan berat total dari struktur atas, sehingga dapat dihitung jumlah pancang yang dibutuhkan dalam satu grup untuk menahan distribusi berat dari struktur di atasnya.

\section{A. Perencanaan Pondasi Metode Konvensional}

Reaksi perletakan untuk metode konvensional diambil dari 
permodelan struktur dengan perletakan jepit. Reaksi perletakan yang diambil untuk perencanaan merupakan reaksi terbesar dari beberapa kombinasi pembebanan.

Jika beban aksial yang diterima perletakan melebihi daya dukung izin satu tiang, maka diperlukan lebih dari satu tiang pancang. Untuk mengetahui jumlah tiang pancang yang dibutuhkan dalam satu titik perletakan (satu kolom) adalah dengan membagi beban aksial dengan daya dukung izin satu tiang. Besarnya daya dukung izin satu tiang ditentukan dari besarnya daya dukung izin tanah sesuai kedalaman $(21 \mathrm{~m}$ untuk end bearing dan $16 \mathrm{~m}$ untuk friction).

Jumlah tiang pancang rencana atau perkiraan awal sebelum dilakukan perhitungan grup adalah sebagai berikut:

$$
n_{\text {perkiraan }}=\frac{P}{Q_{\text {izin }}}
$$

Setelah diketahui jumlah perkiraan awal tiang pancang yang dibutuhkan sesuai dengan beban aksial yang diterima titik perletakan dan kekuatan daya dukungnya. Pada saat sebuah tiang merupakan bagian dari sebuah grup, daya dukungnya mengalami modifikasi, karena pengaruh dari konfigurasi dan jarak antar tiang tersebut. Besarnya daya dukung grup ditentukan dari nilai efisiensi grup (Ce) yang dihitung menggunakan persamaan Converse-Labarre [6] :

$$
C e=1-\left\{1-\left(\frac{\arctan (\varnothing / S)}{90^{\circ}}\right) \times\left(2-\frac{1}{m}-\frac{1}{n}\right)\right\}
$$

Sehingga nilai daya dukung grup adalah :

$$
Q_{\text {grup }}=Q_{\text {izin }} \times \mathrm{n} \times \mathrm{Ce}
$$

Dari perhitungan grup tiang pancang didapatkan jumlah tiang pancang yang memenuhi persyaratan daya dukung.

Selain harus memenuhi daya dukung grup, tiang pancang juga harus memenuhi kekuatan lateral yang ditunjukkan dengan kontrol momen dan defleksi tiang pancang sesuai NAVFAC DM-7 [5].

Langkah perhitungan kekuatan lateral adalah :

1) Perhitungan faktor kekakuan relatif/ relative stiffness factor $(\mathrm{T})$

$$
T=\left(\frac{E I}{f}\right)^{\frac{1}{5}}
$$

2) Mencari nilai koefisien momen $\left(F_{m}\right)$ dan koefisien defleksi $\left(\mathrm{F}_{\delta}\right)$

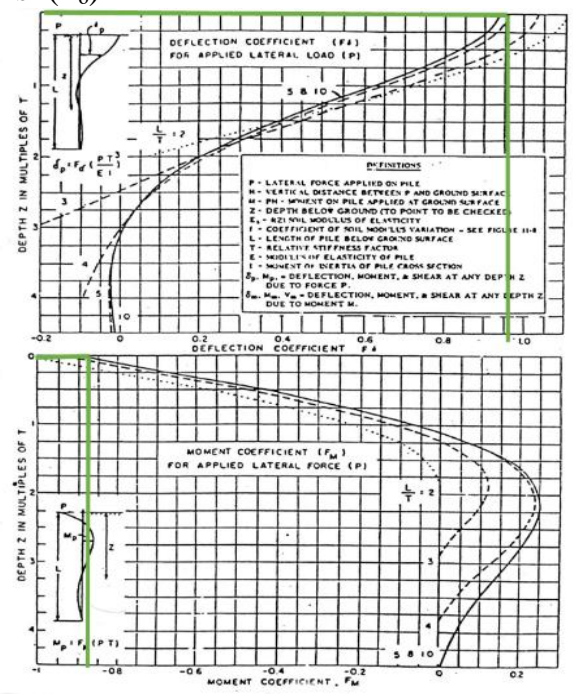

Gambar 3. Grafik untuk mencari nilai $\mathrm{Fm}$ dan $\mathrm{F}_{\delta}$.

3) Menghitung besarnya momen dan defleksi

Besar nilai momen maksimal yang terjadi adalah:

$$
M \max =F m \times T \times P h
$$

Besar defleksi yang terjadi adalah :

$$
\delta=F_{\delta}\left(\frac{P h . T}{E I}\right)^{3}
$$

4) Kontrol momen dan defleksi

Untuk kontrol momen syaratnya adalah :

$$
\text { Mmax } \leq \text { Mcrack }
$$

Sedangkan kontrol defleksi syaratnya adalah :

$$
\delta \leq 2,54 \mathrm{~cm}
$$

Jumlah tiang pancang untuk metode konvensional adalah sebagai berikut.

Tabel 3.

Jumlah tiang pancang metode konvensional End Bearing

\begin{tabular}{ccccccccccccccc}
\hline \hline Axis & A & B & C & D & E & F & G & H & I & J & K & L & M & N \\
\hline 1 & 2 & 3 & 3 & 3 & 3 & 3 & 3 & 3 & 3 & 3 & 3 & 3 & 3 & 2 \\
2 & 3 & 4 & 4 & 4 & 4 & 4 & 4 & 4 & 4 & 4 & 4 & 4 & 4 & 3 \\
3 & 3 & 4 & 4 & 4 & 4 & 4 & 4 & 4 & 4 & 4 & 4 & 4 & 4 & 3 \\
4 & 3 & 4 & 4 & 4 & 4 & 4 & 4 & 4 & 4 & 4 & 4 & 4 & 4 & 3 \\
5 & 3 & 4 & 4 & 3 & 3 & 3 & 3 & 3 & 3 & 3 & 3 & 4 & 4 & 3 \\
6 & 4 & 4 & 4 & 4 & 3 & 3 & 3 & 3 & 3 & 3 & 4 & 4 & 4 & 4 \\
7 & 3 & 4 & 4 & 4 & 3 & 3 & 3 & 3 & 3 & 3 & 4 & 4 & 4 & 3 \\
8 & 4 & 4 & 4 & 4 & 3 & 3 & 3 & 3 & 3 & 3 & 4 & 4 & 4 & 4 \\
9 & 3 & 4 & 4 & 3 & 3 & 3 & 3 & 3 & 3 & 3 & 3 & 4 & 4 & 3 \\
10 & 3 & 4 & 4 & 4 & 4 & 4 & 4 & 4 & 4 & 4 & 4 & 4 & 4 & 3 \\
11 & 3 & 4 & 4 & 4 & 4 & 4 & 4 & 4 & 4 & 4 & 4 & 4 & 4 & 3 \\
12 & 3 & 4 & 4 & 4 & 4 & 4 & 4 & 4 & 4 & 4 & 4 & 4 & 4 & 3 \\
13 & 2 & 3 & 3 & 3 & 3 & 3 & 3 & 3 & 3 & 3 & 3 & 3 & 3 & 2 \\
\hline \hline
\end{tabular}

Tabel 4.

Jumlah Tiang Pancang Metode Konvensional Friction

\begin{tabular}{ccccccccccccccc}
\hline \hline Axis & $\mathrm{A}$ & $\mathrm{B}$ & $\mathrm{C}$ & $\mathrm{D}$ & $\mathrm{E}$ & $\mathrm{F}$ & $\mathrm{G}$ & $\mathrm{H}$ & $\mathrm{I}$ & $\mathrm{J}$ & $\mathrm{K}$ & $\mathrm{L}$ & $\mathrm{M}$ & $\mathrm{N}$ \\
\hline 1 & 6 & 7 & 7 & 7 & 7 & 8 & 9 & 9 & 8 & 7 & 7 & 7 & 7 & 6 \\
2 & 7 & 9 & 9 & 9 & 9 & 10 & 11 & 11 & 10 & 9 & 9 & 9 & 9 & 7 \\
3 & 7 & 9 & 9 & 9 & 9 & 11 & 11 & 11 & 11 & 9 & 9 & 9 & 9 & 7 \\
4 & 8 & 9 & 9 & 9 & 9 & 10 & 10 & 10 & 10 & 9 & 9 & 9 & 9 & 8 \\
5 & 8 & 11 & 10 & 8 & 6 & 7 & 7 & 7 & 7 & 8 & 8 & 10 & 11 & 8 \\
6 & 9 & 11 & 11 & 9 & 6 & 7 & 7 & 7 & 7 & 9 & 9 & 11 & 11 & 9 \\
7 & 8 & 10 & 11 & 9 & 7 & 7 & 7 & 7 & 7 & 9 & 9 & 11 & 10 & 8 \\
8 & 9 & 11 & 11 & 9 & 6 & 7 & 7 & 7 & 7 & 9 & 9 & 11 & 11 & 9 \\
9 & 8 & 11 & 10 & 8 & 6 & 7 & 7 & 7 & 7 & 8 & 8 & 10 & 11 & 9 \\
10 & 8 & 9 & 9 & 9 & 9 & 10 & 10 & 10 & 10 & 9 & 9 & 9 & 9 & 9 \\
11 & 7 & 9 & 9 & 9 & 9 & 11 & 11 & 11 & 11 & 9 & 9 & 9 & 9 & 7 \\
12 & 7 & 9 & 9 & 9 & 9 & 10 & 11 & 11 & 10 & 9 & 9 & 9 & 9 & 7 \\
13 & 6 & 7 & 7 & 7 & 7 & 8 & 9 & 9 & 8 & 7 & 7 & 7 & 7 & 6 \\
\hline \hline
\end{tabular}

\section{B. Perencanaan Pondasi Metode P-Z Curve}

Reaksi perletakan untuk metode $P-Z$ Curve diambil dari permodelan struktur dengan perletakan pegas (spring). Reaksi perletakan yang diambil untuk perencanaan merupakan reaksi terbesar dari beberapa kombinasi pembebanan.

Berdasarkan hasil reaksi perletakan, didapat nilai penurunan $(\delta)$ dari data UZ perletakan. Nilai penurunan aktual yang terjadi dikontrol apakah sudah memiliki penurunan yang cukup merata, dengan perbedaan penurunan yang terjadi maksimal 0,6 cm [7].

Dari nilai reaksi perletakan vertikal dicari perkiraan jumlah tiang pancang, dalam hal ini jumlah asumsi spring yang dibutuhkan untuk tiap perletakan. Perhitungan jumlah spring untuk setiap perletakan ini sama seperti perhitungan jumlah perletakan pada metode konvensional. Nilai reaksi vertikal lalu dibagi dengan $\mathrm{Q}_{\text {izin }}$ untuk mendapatkan nilai gaya aksial yang diizinkan.

Dari nilai $\mathrm{P}$ lalu dicari $\delta$ dengan grafik load-settlement. Setelah didapatkan $\mathrm{P}$ dan $\delta$, maka dicari nilai konstanta pegas (K) dari perletakan [7].

$$
K_{i}=\frac{F i}{\delta_{i}}
$$

Perhitungan konstanta pegas baru di atas dilakukan pada semua titik perletakan. Setelah input semua nilai K baru pada ETABS, dilakukan analisis struktur. Dari analisis struktur didapat nilai reaksi perletakan vertikal (FZ) yang baru dan 
nilai displacement vertikal/ penurunan (UZ) yang baru. Jika penurunan yang terjadi (UZ) masih memiliki perbedaan yang cukup besar, maka dilakukan iterasi pembebanan.

Berdasarkan perhitungan iterasi pembebanan, diketahui jumlah kebutuhan tiang pancang (spring), lalu dilakukan perhitungan grup tiang pancang. Pada perencanaan metode $P$ $Z$ Curve ini, dipakai konfigurasi dan perhitungan yang sama dengan metode konvensional.

Perbedaan perhitungan grup tiang pancang dengan metode konvensional adalah tidak adanya kontrol momen dan defleksi, karena pada perencanaan metode $P-Z$ Curve ini perletakannya berupa pegas sehingga tidak menghasilkan reaksi perletakan horizontal dan momen. Hal ini menyebabkan nilai momen dan defleksi pada tiang pancang diasumsikan nol.

Setelah dilakukan perhitungan grup tiang pancang, maka didapat revisi jumlah tiang pancang (spring). Dari revisi jumlah tiang pancang tersebut dilakukan iterasi lagi untuk mengontrol apakah dengan jumlah tiang pancang sekian beban yang bekerja sudah terdistribusi sehingga menghasilkan penurunan tanah yang merata.

Setelah dilakukan kontrol grup tiang pancang dan iterasi dari jumlah spring yang sudah memenuhi persyaratan grup tiang pancang, diperoleh jumlah spring/ tiang pancang yang dipakai untuk perencanaan ini.

\section{ANALISIS BIAYA}

Berdasarkan hasil analisis struktur atas dan perencanaan pondasi maka didapatkan dimensi struktur atas dan jumlah kebutuhan pondasi tiang pancang untuk masing-masing metode perencanaan pondasi. Dari hasil dimensi dan jumlah pondasi maka dilakukan perhitungan estimasi biayayang dibutuhkan untuk pembangunan gedung modifikasi Puncak MERR Surabaya sesuai metode perencanaan yang digunakan.

Untuk struktur atas gedung, biaya yang dihitung adalah biaya bahan yang digunakan untuk pembangunan struktur pelat, balok anak, balok induk, dan kolom. Bahan yang digunakan adalah beton bertulang. Metode pelaksanaan seperti alat yang digunakan dan bekisting tidak dihitung. Acuan untuk harga beton untuk perhitungan biaya ini adalah HSPK Kota Surabaya 2018 [8]. Perhitungan biaya struktur atas dapat dilihat pada Tabel 5 .

Tabel 5.

Perhitungan Biaya untuk Semua Elemen Struktur Atas

\begin{tabular}{|c|c|c|c|c|c|c|c|}
\hline \multirow[t]{2}{*}{ Elemen } & Dimensi & Panjang/tebal & Jumlah & Volume & Volume & $\begin{array}{l}\text { Harga } \\
\text { Satuan }\end{array}$ & Biaya \\
\hline & $(\mathrm{cm} \mathrm{x} \mathrm{cm})$ & $\mathrm{L}(\mathrm{cm})$ & $\mathrm{n}$ & $\mathrm{cm} 3$ & $\mathrm{~m} 3$ & $\mathrm{Rp} / \mathrm{m} 3$ & $\mathrm{Rp}$ \\
\hline \multirow{2}{*}{ Kolom 1} & \multirow{2}{*}{$60 \times 60$} & 350 & 88 & 110880000 & 110,88 & Rp1.381.964 & Rp153.232.168 \\
\hline & & 300 & 264 & 285120000 & 285,12 & Rp1.381.964 & Rp394.025.576 \\
\hline \multirow{2}{*}{ Kolom 2} & \multirow{2}{*}{$55 \times 55$} & 350 & 46 & 48702500 & 48,7025 & Rp1.381.964 & Rp67.305.102 \\
\hline & & 300 & 714 & 647955000 & 647,955 & Rp1.381.964 & Rp895.450.484 \\
\hline \multirow{2}{*}{ Kolom 3} & \multirow{2}{*}{$50 \times 50$} & 350 & 16 & 14000000 & 14 & Rp1.381.964 & Rp19.347.496 \\
\hline & & 300 & 384 & 288000000 & 288 & Rp1.381.964 & Rp398.005.632 \\
\hline \multirow{5}{*}{ Balok 1} & \multirow{5}{*}{$40 \times 60$} & 350 & 120 & 87840000 & 87,84 & Rp1.160.338 & Rp101.924.090 \\
\hline & & 340 & 420 & 342720000 & 342,72 & Rp1.160.338 & Rp397.671.039 \\
\hline & & 445 & 112 & 119616000 & 119,616 & Rp1.160.338 & Rp138.794.990 \\
\hline & & 480 & 880 & 1013760000 & 1013,76 & Rp1.160.338 & Rp1.176.304.251 \\
\hline & & 500 & 836 & 1003200000 & 1003,2 & Rp1.160.338 & Rp1.164.051.082 \\
\hline \multirow{5}{*}{ Balok 2} & \multirow{5}{*}{$35 \times 50$} & 305 & 106 & 56577500 & 56,5775 & Rp1.160.338 & Rp65.649.023 \\
\hline & & 340 & 174 & 103530000 & 103,53 & Rp1.160.338 & Rp120.129.793 \\
\hline & & 445 & 124 & 96565000 & 96,565 & Rp1.160.338 & Rp112.048.039 \\
\hline & & 480 & 308 & 258720000 & 258,72 & Rp1.160.338 & Rp300.202.647 \\
\hline & & 500 & 201 & 175875000 & 175,875 & Rp1.160.338 & Rp204.074.446 \\
\hline \multirow{3}{*}{ Balok Anak } & \multirow{3}{*}{$30 \times 40$} & 445 & 40 & 21360000 & 21,36 & Rp1.160.338 & Rp24.784.820 \\
\hline & & 480 & 500 & 288000000 & 288 & Rp1.160.338 & Rp334.177.344 \\
\hline & & 500 & 80 & 48000000 & 48 & Rp1.160.338 & Rp55.696.224 \\
\hline Pelat 0 & 31347900 & 20 & 1 & 626958000 & 626,958 & Rp1.160.338 & Rp727.483.192 \\
\hline Pelat 1 & 31347900 & 15 & 3 & 1410655500 & 1410,6555 & Rp1.160.338 & Rp1.636.837.182 \\
\hline Pelat 2 & 22360000 & 15 & 6 & 2012400000 & 2012,4 & Rp1.160.338 & Rp2.335.064.191 \\
\hline Pelat 3 & 27347900 & 15 & 1 & 410218500 & 410,2185 & Rp1.160.338 & Rp475.992.114 \\
\hline \multirow[t]{2}{*}{ Pelat 4} & 4000000 & 15 & 1 & 60000000 & 60 & Rp1.160.338 & Rp69.620.280 \\
\hline & & & Total & & & & Rp11.367.871.204 \\
\hline
\end{tabular}

Untuk pondasi, biaya yang dihitung adalah harga tiang pancang yang dibutuhkan, biaya pemancangan, dan biaya pengelasan jika diperlukan lebih dari satu tiang pancang pada satu titik. Perhitungan biaya tiang pancang didapat dari HSPK Kota Surabaya 2018 [8] dan penelusuran referensi [3],[9] adalah sebagai berikut: harga pemancangan Rp. 411.903-/m; harga pengelasan Rp. 672.552-/ titik; harga pemotongan Rp. 271.570-/m; dan harga untuk satu batang tiang pancang sepanjang 16 meter Rp.6.700.000, -/batang.

Berdasarkan hasil perhitungan biaya, dibuat Tabel rekapitulasi biaya total untuk gedung modifikasi Puncak MERR Surabaya untuk masing-masing metode perencanaan yang ditunjukkan pada Tabel 6 . 
Tabel 6.

Rekapitulasi Biaya Total untuk Setiap Metode Perencanaan

\begin{tabular}{ccccc}
\hline \hline Metode & Jumlah Tiang & Biaya Struktur Atas & Biaya Pondasi & Biaya Total \\
\hline $\begin{array}{c}\text { Konvensional End Bearing } \\
\text { Konvensional Friction }\end{array}$ & 644 & Rp11.367.871.204 & Rp16.557.101.640 & Rp27.924.972.844 \\
$\begin{array}{c}\text { P-Z Curve End Bearing 0,3 } \\
\text { Ult }\end{array}$ & 1562 & Rp11.367.871.204 & Rp20.759.679.776 & Rp32.127.550.980 \\
$\begin{array}{c}\text { P-Z Curve End Bearing 0,5 } \\
\text { Ult }\end{array}$ & 698 & Rp11.367.871.204 & Rp17.945.430.038 & Rp29.313.301.242 \\
$\begin{array}{c}\text { P-Z Curve End Bearing 0,7 } \\
\text { Ult }\end{array}$ & 404 & Rp11.367.871.204 & Rp10.386.753.203 & Rp21.754.624.407 \\
$\begin{array}{c}\text { P-Z Curve End Bearing 0,9 } \\
\text { Ult }\end{array}$ & 318 & Rp11.367.871.204 & Rp8.175.711.679 & Rp19.543.582.883 \\
$\begin{array}{c}\text { P-Z Curve Friction 0,3 Ult } \\
\text { P-Z Curve Friction 0,5 Ult }\end{array}$ & 1718 & Rp11.367.871.204 & Rp5.501.894.023 & Rp16.869.765.227 \\
P-Z Curve Friction 0,7 Ult & 722 & Rp11.367.871.204 & Rp13.742.323.232 & Rp25.110.194.436 \\
P-Z Curve Friction 0,9 Ult & 536 & Rp11.367.871.204 & Rp9.595.703.456 & Rp20.963.574.660 \\
\hline \hline
\end{tabular}

\section{KESIMPULAN}

Berdasarkan analisis dan pembahasan yang dilakukan dalam perencanaan ini, maka dapat diambil kesimpulan sebagai berikut:

1) Struktur gedung modifikasi Apartemen Puncak MERR dimodifikasi menjadi 10 lantai dan dilakukan modifikasi dimensi elemen struktur yang terdiri dari kolom $160 \mathrm{x}$ $60 \mathrm{~cm}^{2}$, kolom $255 \times 55 \mathrm{~cm}^{2}$, kolom $350 \times 50 \mathrm{~cm}^{2}$, balok $140 \times 60 \mathrm{~cm}^{2}$, balok $230 \times 50 \mathrm{~cm}^{2}$, balok anak $30 \times 40$ $\mathrm{cm}^{2}$, pelat 0 tebal $20 \mathrm{~cm}$, pelat $1 \mathrm{~s} / \mathrm{d}$ pelat 4 tebal disamakan $15 \mathrm{~cm}$. Hasil Analisis struktur menunjukkan hasil modifikasi gedung dapat dipakai untuk perencanaan.

2) Metode perencanaan yang digunakan yaitu konvensional jepit dan $P-Z$ curve pegas. Untuk gedung modifikasi Apartemen Puncak MERR yang tidak simetris pada perencanaan ini, didapat hasil analisis struktur didapatkan momen yang dihasilkan pada metode konvensional hampir sama momen pada metode $P-Z$ curve. Variasi daya dukung yang digunakan pada perencanaan ini yaitu $\mathrm{SF}=3$ untuk metode konvensional dan $\mathrm{Q}_{\text {izin }}=0,3 \mathrm{Q}_{\text {ult }}, \mathrm{Q}_{\mathrm{izin}}=0,5 \mathrm{Q}_{\text {ult }}, \mathrm{Q}_{\mathrm{izin}}=0,7 \mathrm{Q}_{\text {ult }}$, dan $\mathrm{Q}_{\mathrm{izin}}=0,9 \mathrm{Q}_{\mathrm{ult}}$ pada metode $P-Z$ curve.

3) Perencanaan pondasi tiang pancang menggunakan spun pile diameter $60 \mathrm{~cm}$. Kedalaman tanah daya dukung yaitu $21 \mathrm{~m}$ untuk pondasi end bearing dan $16 \mathrm{~m}$ untuk pondasi friction. Jumlah kebutuhan tiang pancang yaitu:

Tabel 7.

Jumlah tiang pancang untuk masing-masing metode perencanaan

\begin{tabular}{cc}
\hline Metode & Jumlah Tiang \\
\hline Konvensional End Bearing & 644 \\
Konvensional Friction & 1562 \\
P-Z Curve End Bearing 0,3 Ult & 698 \\
P-Z Curve End Bearing 0,5 Ult & 404 \\
P-Z Curve End Bearing 0,7 Ult & 318 \\
P-Z Curve End Bearing 0,9 Ult & 214 \\
P-Z Curve Friction 0,3 Ult & 1718 \\
P-Z Curve Friction 0,5 Ult & 1034 \\
P-Z Curve Friction 0,7 Ult & 722 \\
P-Z Curve Friction 0,9 Ult & 536 \\
\hline
\end{tabular}

4) Defleksi dan retak yang terjadi pada balok untuk semua metode perencanaan telah memenuhi persyaratan yaitu kurang dari 480/panjang balok untuk defkleksi dan kurang dari 0,4 (balok interior) atau 0,3 (balok eksterior) untuk retak, sehingga tidak perlu dilakukan perubahan dimensi struktur.

5) Biaya total untuk gedung modifikasi Puncak MERR Surabaya untuk masing-masing metode perencanaan adalah sebagai berikut:

Tabel 8.

Biaya Total untuk Masing-masing Metode Perencanaan

\begin{tabular}{cc}
\hline \hline Metode & Biaya Total \\
\hline Konvensional End Bearing & Rp27.924.972.844 \\
Konvensional Friction & Rp32.127.550.980 \\
P-Z Curve End Bearing 0,3 Ult & Rp29.313.301.242 \\
P-Z Curve End Bearing 0,5 Ult & Rp21.754.624.407 \\
P-Z Curve End Bearing 0,7 Ult & Rp19.543.582.883 \\
P-Z Curve End Bearing 0,9 Ult & Rp16.869.765.227 \\
P-Z Curve Friction 0,3 Ult & Rp34.200.860.868 \\
P-Z Curve Friction 0,5 Ult & Rp25.110.194.436 \\
P-Z Curve Friction 0,7 Ult & Rp20.963.574.660 \\
P-Z Curve Friction 0,9 Ult & Rp18.491.551.332 \\
\hline \hline
\end{tabular}

Saran untuk perhitungan pondasi dengan metode perencanaan ini adalah sebagai berikut:

1) Untuk menghemat biaya pembangunan gedung modifikasi Apartemen Puncak MERR maka digunakan pondasi tiang pancang dengan metode $P-Z$ Curve tumpuan end bearing dengan $\mathrm{Q}_{\mathrm{izin}}=0,9 \mathrm{Q}_{\mathrm{ult}}$ sebesar $\mathrm{Rp}$. 16.869.765.22, - .

2) Pada konfigurasi struktur yang tidak simetris seperti pada gedung modifikasi Apartemen Puncak MERR ini, disarankan menggunakan metode $P-Z$ Curve karena tidak perlu dilakukan perubahan dimensi struktur untuk mencapai penurunan merata sehingga perhitungan lebih cepat dan mendapat jumlah kebutuhan pondasi tiang pancang lebih sedikit.

\section{DAFTAR PUSTAKA}

[1] Badan Pusat Statistik, "Perkembangan Jumlah Kendaraan Bermotor Menurut Jenis Tahun 1949-2016.," 2018. [Online]. Available: https://www.bps.go.id/linkTableDinamis/view/id/1133.

[2] WIKA, "Laporan Perhitungan Struktur dan Gambar Desain Perencanaan."

[3] D. R. Sandra, "Analisis Perbandingan Perencanaan Pondasi Tiang Pancang Menggunakan Metode Konvensional dan Metode P-Y Curve pada Lapisan Tanah Lunak yang Teball: Studi Kasus Kota Banjarmasin dengan Kedalaman Tanah Keras 40 Meter,” 2015.

[4] C. Software, "All Pile Version 7 User Manual," CivilTech Software.

[5] "NAVFAC DM7.01 Soil Mechanics."

[6] Herman Wahyudi, Daya Dukung Pondasi Dalam. 
[7] Y. Lastiasih and I. B. Mochtar, "Usulan Metoda Perhitungan Interaktif Struktur Pondasi di Atas Tanah Lunak dengan Menyertakan Pengaruh Penurunan Konsolidasi Jangka Panjang," MEDIA Komun. Tek. SIPIL, vol. 16, no. 2, pp. 160-170, 2008.

[8] "LPSE Kota Surabaya.".

[9] Felix Cahyo Kuncoro Jakti, "Analisis Perbandingan Biaya dan Waktu Pelaksanaan Tiang Pancang dan Tiang Bor Studi Kasus Perencanaan Rumah Sakit Kelas B Bandung." 